\title{
Identification of the Strong Factor that Influence the Improvement of the Primary Education using the Evidential Reasoning
}

\author{
Mohammad Salah Uddin Chowdury \\ Department of Computer Science \& Engineering \\ BGC Trust University Bangladesh \\ Chittagong, Bangladesh
}

\author{
Smita Sarker \\ Department of Computer Science \& Engineering \\ BGC Trust University Bangladesh \\ Chittagong, Bangladesh
}

\begin{abstract}
Primary education is one of the important social sectors in the developing countries. It plays a gigantic role in promoting the social development of the concerned countries. More specifically, not the only education but the quality primary education which depends on such factors will contribute a lot for its smooth acceleration. In primary education, if the quality will maintain then automatically all the problems in primary education i.e. enrollment, completion, drop-out and so on will be robotic and gradually solved. The improvement primary education is influenced by both multiple qualitative and quantitative factors. This paper presents evidential reasoning(ER) approach to find out significant factors that are aggregated in assessment of performance of primary education. A case study of Dhaka, Chittagong, Rajshahi and Khulna districts in Bangladesh is provided to illustrate the implementation process of the ER approach for finding strong factors of primary education. For that reason, firstly we assess the performance of four districts then we determine the weakness and strength of specific factors of particular district. In this paper we also show the relation of lowest or best performing districts to its specific factors.
\end{abstract}

Keywords- Assessment; evidential reasoning; district-wise primary education; factors; key performance indicator (KPI); multiple attribute decision analysis (MADA); uncertainty; utility interval.

\section{INTRODUCTION}

A Primary education in Bangladesh that is the largest unitary authorities in the world plays an important role in education system. In order to improve primary education Bangladesh government has undertaken a lot of necessary steps. The Primary and Mass Education Division (PMED) prepared in 1997 a comprehensive Primary Education Development Program (PEDP) which aimed at enhancement of education planning and management capacity, increasing equitable access to primary schooling and improvement of the quality of primary education through its several projects [10]. In the World Education Forum held at Dakar, Senegal in April 2000, the government of Bangladesh has committed to achieve of Education for All goals and every citizen by the year 2015[12]. Now 75\% of total schools are controlled by the government and around $83 \%$ of the total children enrolled in the primary level educational institution go to these schools
[10], [12]. The quality of primary education is evaluated in terms of the classroom climate, teaching style, classroom management, and understanding the subject matters during the lesson in the class [13]. PEDP-II defines 14 key monitoring indicators, the Key Performance Indicators (KPI) and the Primary School Quality Level (PSQL) indicators which act as the basis for the sector programme performance report, setting expectations that will instill purpose to ongoing monitoring and evaluation activities for the benefit of the planning process [1], [2], [10].

A number of survey reports were published to reflect the performance of primary education of Bangladesh based on some statistical measurement. According to case study of two district of Tamil Nadu it is observed that they assess the primary education with taking few major factors such as completion, repetition, and dropout rates. After analyzing these factors they identify the weaken areas which contribute to the lack of acceptable quality schools and focus the learning environment, school governance and management issues [11].But this assessment procedure do not follow systematic computational methods. For this reason the result is reflected by unwanted uncertainties. At that case, Evidential Reasoning approach is very effective which enable both qualitative and quantitative measurement under the multiple attributes decision analysis [3], [4], [5], 6].

In this paper we select four focus districts as our problem areas where two significant factors of KPI such as enrollment and outcomes are selected for performance measuring factors. The main objective of this paper is to find out the strong factor that influence the performance of primary education best district using ER approach by aggregating basic attributes of these two factors. Finally we show the ranking of district wise primary education as well as their factors.

We organize the research activities as follows. In section 2, we explain the ER approach for ADPE outlined and illustrated by subsequent sub-sections 2.1, and 2.2. The experimental result is outline by section 3.Finaly we concluding our remarks at section 4 in which we show the outcomes of evaluation with the discussion of suggestion of future work. 


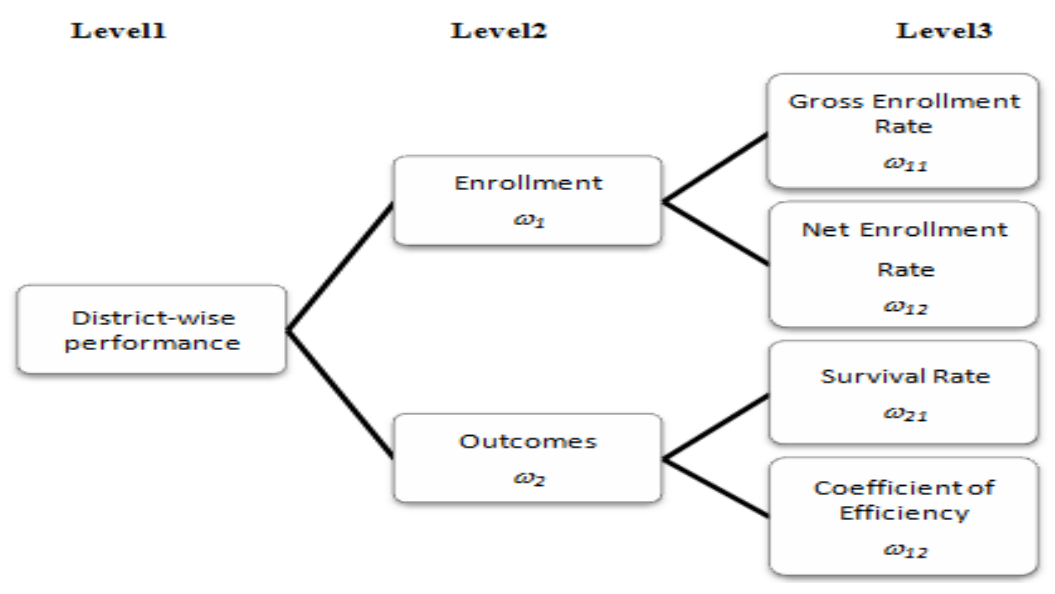

Figure 1. Evaluation hierarchy of the district-wise primary education

TABLE1 1. District wise Comparison of Enrollment and Outcomes (2005-2007)

\begin{tabular}{|c|c|c|c|c|c|}
\hline \multirow[t]{2}{*}{$\begin{array}{l}\text { General } \\
\text { attributes }\end{array}$} & \multirow[t]{2}{*}{$\begin{array}{r}\text { Basic } \\
\text { attributes }\end{array}$} & & \multicolumn{3}{|c|}{$\begin{array}{l}\text { District level Primary Education } \\
\qquad(2005,2006,2007)\end{array}$} \\
\hline & & Dhaka & Chittagong & Rajshahi & Khulna \\
\hline \multirow[t]{2}{*}{ Enrollment } & $\begin{array}{l}\text { Gross } \\
\text { Enrollment } \\
\text { Rate(GER) }\end{array}$ & $87.9 \%, 91.4 \%, 91.2 \%$ & $85.7 \%, 95 \%, 95.3 \%$ & $91.2 \%, 92.2 \%, 93.4 \%$ & $100.4 \%, 97.3 \% 98.1 \%$ \\
\hline & $\begin{array}{l}\text { Net } \\
\text { Enrollment } \\
\text { Rate(NER) }\end{array}$ & $82.7 \%, 87.5 \%, 86.0 \%$ & $84.3 \%, 88.8 \%, 89.6 \%$ & $90.1 \%, 86.5 \%, 88.5 \%$ & $92.9 \%, 91.3 \%, 92.4 \%$, \\
\hline \multirow[t]{2}{*}{ Outcomes } & $\begin{array}{l}\text { Survival } \\
\text { Rate }\end{array}$ & $69.5 \%, 61.6 \%, 47.2 \%$ & $58.1 \%, 63.6 \%, 62.6 \%$ & $53.3 \%, 57.7 \%, 59.9 \%$ & $64.4 \%, 60.3 \%, 63.2 \%$ \\
\hline & $\begin{array}{l}\text { Coefficient } \\
\text { of efficiency }\end{array}$ & $75.2 \%, 67.7 \%, 58.0 \%$ & $61.5 \%, 66.6 \%, 64.8 \%$ & $59 \%, 65.8 \%, 66.7 \%$ & $66.8 \%, 66.1 \%, 65.8 \%$ \\
\hline
\end{tabular}

2. The Evidential Reasoning Approach for Identification strong factors in the Primary Education Assessment

\subsection{Identification of Assessment Factors and Evaluation Grades}

We apply the evidential reasoning approach to analyze the performance of four main districts wise primary education including Dhaka, Chittagong, Rajshahi, and Khulna. Here only qualitative performance attributes are considered for demonstrating purpose. The major performance attributes are considered as enrollment and outcomes. For facilitating the assessment these attributes are further classified basic factors such as gross enrollment, net enrollment, survivable rate and coefficient of efficiency which are shown in the figure 1.

According to School Survey Report 2007 we draw the scenario of primary education of four districts as the following table [1]. Considering the data of three years of the following table 1 we define the evaluation scale as follows:

Gross Enrollment Rate and Net Enrollment Rate

Indifferent (I):80-85\% Average (A): $85-90 \%$, Good (G): 90-95, Excellent (E): 95-100\%
Indifferent (I):45-55\%， Average (A):55-60\%， Good (G):60-65\%, Excellent (E): 65-70\%

Coefficient of efficiency

Indifferent (I):45-55\%, Average (A):55-65\%, Good (G):65-75, Excellent (E): -75-85\%

In the following table 2 we summarize the whole assessment problem where I, A, G, and E indicate the evaluation grades Indifferent, Average, Good and Excellent respectively, and the number in a bracket denotes the degree of a belief to which an attribute is assessed to a grade. Now we consider the primary education of Dhaka district where we use the grades as defined before and represent the following distribution as follows [3] , [4], [5],[6],[7],[8]:

$S($ Gross Enrollment Rate $)=\{($ average, 0.2$),($ good, 0.8$)\} \quad$ (1a)

$S($ Net Enrollment Rate $)=\{($ indifferent, 0.2), (average, 0.8$)\}$ (1b)

$S($ Survival Rate $)=\{$ (average, 09) $\}$

$S($ coefficient of efficiency $)=\{($ average, 0.2$),($ good, 0.6$)\}$

Due to uncertainty some incomplete assessment are shown in the table 2.For example:

\section{Survival Rate}


TABLE 2

Decision matrix for district wise primary level education assessment

\begin{tabular}{|c|c|c|c|c|c|}
\hline \multirow{2}{*}{$\begin{array}{l}\text { General } \\
\text { attribute }\end{array}$} & \multirow{2}{*}{$\begin{array}{l}\text { Basic } \\
\text { attributes }\end{array}$} & \multicolumn{4}{|c|}{ Districts types } \\
\hline & & $\begin{array}{l}\text { Dhaka } \\
\left(a_{1}\right)\end{array}$ & $\begin{array}{l}\text { Chittagong } \\
\left(a_{2}\right)\end{array}$ & $\begin{array}{l}\text { Rajshahi } \\
\left(a_{3}\right)\end{array}$ & $\begin{array}{l}\text { Khulna } \\
\left(a_{4}\right)\end{array}$ \\
\hline \multirow[t]{2}{*}{$\begin{array}{l}\text { Enrollme } \\
\text {-nt } \\
\left(e_{1}\right)\end{array}$} & $\begin{array}{l}\text { gross } \\
\text { enrollment } \\
\text { rate(eni) }\end{array}$ & $\begin{array}{l}\mathrm{A}(.2) \\
\mathrm{G}(.8)\end{array}$ & $\begin{array}{l}\mathrm{A}(.1) \\
\mathrm{G}(.9)\end{array}$ & $\mathrm{G}(1)$ & $\mathrm{E}(1)$ \\
\hline & $\begin{array}{l}\text { net } \\
\text { enrollment } \\
\text { rate }\left(e_{12}\right)\end{array}$ & $\begin{array}{l}\mathrm{I}(.2) \\
\mathrm{A}(.8)\end{array}$ & $\begin{array}{l}\mathrm{I}(.1) \\
\mathrm{A}(.9)\end{array}$ & $\begin{array}{l}\mathrm{A}(.2) \\
\mathrm{G}(.8)\end{array}$ & $G(1)$ \\
\hline \multirow[t]{2}{*}{$\begin{array}{l}\text { Out- } \\
\text { comes } \\
\left(\mathrm{e}_{2}\right)\end{array}$} & $\begin{array}{l}\text { Survival } \\
\text { Rate(ent) }\end{array}$ & $\mathrm{A}(.9)$ & $\begin{array}{l}\mathrm{G}(.8) \\
\mathrm{A}(.2)\end{array}$ & $\begin{array}{l}\mathrm{I}(.1) \\
\mathrm{A}(.9)\end{array}$ & $\mathrm{G}(1)$ \\
\hline & $\begin{array}{l}\text { coefficient } \\
\text { of } \\
\text { efficiency } \\
\left(e_{22}\right)\end{array}$ & $\begin{array}{l}\mathrm{A}(.2) \\
\mathrm{G}(.6)\end{array}$ & $\begin{array}{l}\mathrm{A}(.9) \\
\mathrm{G}(.1)\end{array}$ & $\begin{array}{l}\mathrm{A}(.4) \\
\mathrm{G}(.6)\end{array}$ & $\mathrm{G}(.8)$ \\
\hline
\end{tabular}

The gross enrollment rate of Dhaka is complete because the sum of belief is 1 but the coefficient of efficiency is incomplete because $.8<1$.

\subsection{Computational steps of aggregating assessment}

Firstly we show the total calculation for assessment of enrollment of Dhaka primary education .The enrollment $\left(\mathrm{e}_{1}\right)$ is assessed by two basic attributes: gross enrollment rate $\left(\mathrm{e}_{11}\right)$ and net enrollment rate $\left(\mathrm{e}_{12}\right)$.

From (1a) and (1b), we have

$$
\begin{aligned}
& \beta_{1,1}=0, \quad \beta_{1,2}=0.2, \quad \beta_{1,3}=0.8, \quad \beta_{1,4}=0 \\
& \beta_{2,1}=0.2, \quad \beta_{2,2}=0.8, \quad \beta_{2,3}=0, \quad \beta_{2,4}=0
\end{aligned}
$$

On the basis of importance on the performance of primary education suppose the hypothetical weights for two attributes are: $\omega_{11}=0.55$ and $\omega_{12}=0.45$.

We get the basic and combined probability masses $\left(m_{n, i}\right)$ by using following recursive equations [4], [5], [6], [7], [8]:

$$
\begin{aligned}
& m_{\mathrm{n} . \mathrm{i}}=\omega_{\mathrm{n} .} \beta_{\mathrm{n} . \mathrm{i}} \text { for } \mathrm{i}=1,2 \ldots \mathrm{N} \\
& m_{l, 1}=0 ; \quad m_{2,1}=0.11 ; \quad m_{3,1}=0.44 ; \quad m_{4,1}=0 ; \\
& \bar{m}_{H, 1}=0.45 \quad \tilde{m}_{H, 1}=0 \\
& m_{l, 2}=0.09 ; \quad m_{2,2}=0.36 ; \quad m_{3,2}=0 ; \quad m_{4,2}=0 ; \\
& \bar{m}_{H, 2}=0.55 ; \tilde{m}_{H, 2}=0 \\
& K_{I(2)}=\left[1-\sum_{t=1}^{4} \sum_{\substack{j=1 \\
j \neq t}}^{4} m_{t, I(1)} m_{j, 2}\right]^{-1} \\
& =[1-(0+. .+0+.0099+0.0396+0.1584+0+. .+0)]^{-1} \\
& =[1-.2079]^{-1}=1.2625
\end{aligned}
$$

And $m_{H, i}=\bar{m}_{H, i}+\tilde{m}_{H, i}(\mathrm{i}=1,2)$ now we have

$m_{l, I(2)}=K_{I(2)}\left(m_{l, l}, m_{l, 2}+m_{l, 1}, m_{H, 2}+m_{l, 2} m_{H, I}\right)=1.2625(0+0+0.09 * 0.45)$ $=0.0511$

$m_{2, I(2)}=K_{I(2))}\left(m_{2,1}, m_{2,2}+m_{2,1}, m_{H, 2}+m_{2,2} m_{H, 1}\right)$

$=1.2625(0.11 * 0.36+00.11 * 0.55+0.36 * 0.45)=0.3309$

$m_{3, I(2)}=K_{I(2)}\left(m_{3,1}, m_{3,2}+m_{3,1}, m_{H, 2}+m_{3,2} m_{H, 1}\right)$

$=1.2625(0+0+0.44 * 0.45)=0.3055$

$m_{4, I(2)}=K_{I(2))}\left(m_{4,1}, m_{4,2}+m_{4,1}, m_{H, 2}+m_{4,2} m_{H, 1}\right)=0$

$\bar{m}_{H, I(2)}=K_{I(2)}\left[\bar{m}_{H, I(1)} \bar{m}_{H, 2}\right\rfloor=0.3124$

$\tilde{m}_{H, I(2)}=K_{I(2)}\left\lfloor\tilde{m}_{H, I(1)} \tilde{m}_{H, 2}+\bar{m}_{H, I(1)} \tilde{m}_{H, 2}+\tilde{m}_{H, I(1)} \bar{m}_{H, 2}\right\rfloor=0$

Now the combined degrees of belief are calculated by using equation as follows [4], [5], [6], [7], [8]:

$$
\begin{aligned}
& \beta_{1}=\frac{m_{1, I(2)}}{1-\bar{m}_{H, I(2)}}=\frac{0.0511}{1-0.3124}=0.0743 \\
& \beta_{2}=\frac{m_{2, I(2)}}{1-\bar{m}_{H, I(2)}}=\frac{0.3309}{1-0.3124}=0.4812 \\
& \beta_{3}=\frac{m_{3, I(2)}}{1-\bar{m}_{H, I(2)}}=\frac{0.3055}{1-0.3124}=0.4443 \\
& \beta_{4}=\frac{m_{4, I(2)}}{1-\bar{m}_{H, I(2)}}=0 \\
& \beta_{H}=\frac{\tilde{m}_{H, I(2)}}{1-\bar{m}_{H, I(2)}}=0
\end{aligned}
$$

Then the enrollment rate of primary education of Dhaka district is assessed by

$\mathrm{S}$ (enrollment rate)

$=\{$ (indifferent, 0.0743), (average, 0.4812), $0.4443)\}$

(good,

After repeating above procedures we assess the outcomes attribute as follows:

$\mathrm{S}$ (outcomes)

$=\{$ (average, 0.7094$),($ good, 0.1751$)\}$

Finally the performance of Dhaka district primary education is assessed by enrollment $\left(\mathrm{e}_{1}\right)$ and outcomes $\left(\mathrm{e}_{2}\right)$ as shown in table 3.

TABLE 3

Assigned weights, beliefs and calculated probability masses for level 2 attributes of Dhaka

\begin{tabular}{|l|l|l|l|l|l|l|l|l|l|l|l|l|}
\hline Attributes & Weight & \multicolumn{9}{|c|}{ Belief } & \multicolumn{6}{|c|}{ Probability Mass } \\
\hline & $\omega_{4}$ & $\beta_{1,4}$ & $\beta_{2,}$ & $\beta_{3,4}$ & $\beta_{4,}$ & $\mathrm{~m}_{1,}$ & $\mathrm{~m}_{2,}$ & $\mathrm{~m}_{3,4}$ & $\mathrm{~m}_{4,}$ & $\mathrm{~m}_{H, 4}$ & $\mathrm{~m}_{\mathrm{H},}$ & $\mathrm{m}_{\mathrm{H},}$ \\
\hline $\begin{array}{l}\text { enrollment } \\
\left(\mathrm{e}_{1}\right)\end{array}$ & .5 & .0743 & .4821 & .4443 & 0 & .0372 & .2412 & .2222 & 0 & .5 & .5 & 0 \\
\hline $\begin{array}{l}\text { Outcomes } \\
\left(\mathrm{e}_{2}\right)\end{array}$ & .5 & 0 & .7094 & .1751 & 0 & 0 & .3547 & .0876 & 0 & .5577 & .5 & 0.0577 \\
\hline
\end{tabular}


By using above similar actions we find the assessment degree of for Dhaka district as follows:

$S($ Dhaka $)=$ ( (indifferent, 0.0328$)$, (average, 0.6272) , (good, 0.2954) \}

Similarly we can generate the overall assessment of primary education of other three districts such as Chittagong, Rajshahi and Khulna:

$S($ Chittagong $)=\{($ indifferent, 0.0153$),($ average, 0.4381$)$, (good, 0.5467) \}

$S($ Rajshahi $)=\{($ indifferent, 0.0271$)$, (average, 0.4034$)$, (good, 0.5695) \}

$S($ Khulna $)=\{(($ good, 0.7281$),($ excellent, 0.2613$)\}$

According to the statements $3 \mathrm{a}-3 \mathrm{~d}$ we show the distributed district-wise performance of our given four districts in the following figure 3 .

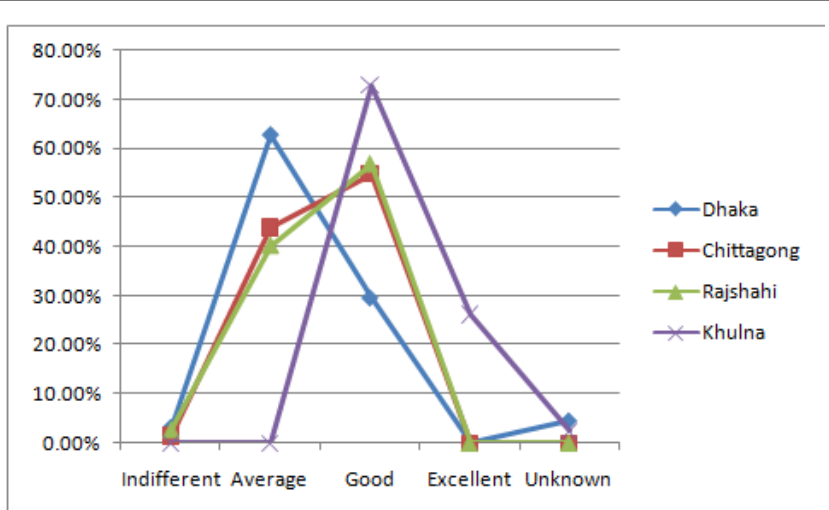

Figure 2. Distributed Assessment of District-wise performance

\section{EXPERIMENTAL RESULTS AND ANALYSIS}

To precisely rank the four districts, their utilities need to be estimated. To do so, the utilities of the four individual evaluation grades need to be estimated first. The above partial rankings of alternatives could be used to formulate regression models for estimating the utilities of grades [4],[5].[6],[7],[8]. The maximum, minimum, and the average expected utility on the particular districts are given on the table 4 .

TABLE 4

Utilities on district wise performance

\begin{tabular}{|l|l|l|l|l|}
\hline & $U_{\operatorname{man}}$ & $U_{\max }$ & $U_{\text {avg }}$ & Rank \\
\hline Dhaka & 0.4049 & 0.4548 & 0.4321 & 4 \\
\hline Chittagong & 0.5109 & 0.5109 & 0.5109 & 3 \\
\hline Rajshahi & 0.5147 & 0.5147 & 0.5147 & 2 \\
\hline Khulna & 0.7491 & 0.7730 & 0.7611 & 1 \\
\hline
\end{tabular}

Now from above analysis it clear that the performance ranking of four district-wise primary education is stated as follows.

Khulna $>$ Rajshahi $>$ Chittagong $>$ Dhaka
Now we identify the strong entity of best performing district Khulna with considering the table 5.Firstly we compute the utility of these factors then we rank the factors on basis on their utility value.

Using the following formula we find out the maximum, minimum and average utilities of particular factor.

$$
\begin{aligned}
& u_{\text {max }}(y)=\sum_{n=1}^{N-1} \beta_{n} u\left(H_{n}\right)+\left(\beta_{N}+\beta_{H}\right) u\left(H_{N}\right) \\
& u_{\text {min }}(y)=\left(\beta_{1}+\beta_{H}\right) u\left(H_{1}\right)+\sum_{n=2}^{N} \beta_{n} u\left(H_{n}\right) \\
& u_{\text {avg }}(y)=\frac{u_{\text {max }}(y)-u_{\text {min }}(y)}{2} .
\end{aligned}
$$

TABLE 5. Utility and Rank of the Factors

\begin{tabular}{|c|c|c|c|c|}
\hline & $\mathrm{U}_{\min }$ & $\mathrm{U}_{\max }$ & $\mathrm{U}_{\text {avg }}$ & Rank \\
\hline Enrollment & 0.8677 & 0.8677 & 0.8677 & 1 \\
\hline Outcomes & 0.6418 & 0.6839 & 0.6629 & 2 \\
\hline
\end{tabular}

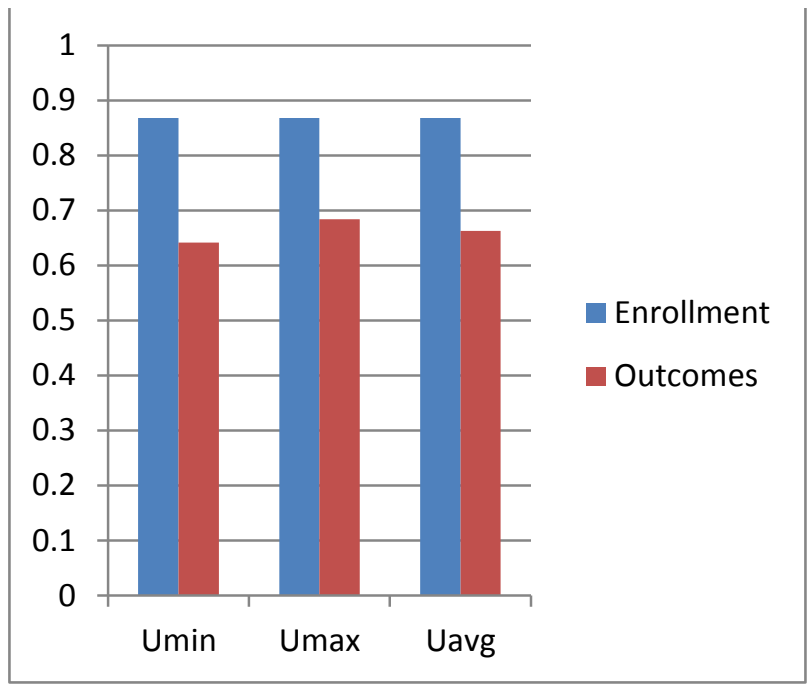

Figure 3. Utility interval of the factors

Considering the equations we find the results which shown the table 5. Hence we the rank of the factor is as follow.

\section{Enrollment>Outcomes}

\section{CONCLUSION}

Primary Education requires many qualitative and quantitative attributes in their assessment which need strong methodologies in order to find out their significant impact. In this paper we apply evidential reasoning approach that is appropriate for such attributes assessment under uncertainties. Because of major role in the assessment of primary education we focus our attention on two attributes i.e. enrollment and outcomes which are successfully aggregated by ER approach. The uncertainties among various attribute of particular district are properly handled by our suggested approach. On the above study we summarize that the performance of Khulna district is highest among all other districts. In the case of particular 
district assessment process the relative importance of each attribute is also measured by identifying the strengths and weakness of it's on each district. In this paper we identify that the enrollment $f$ the strong factor of Khulna district primary education. For that reason it is clear that if we increase the enrollment rate particular district then the performance of the primary education of this district is stronger. We present the result of an individual district in the form of interval from minimum utility to maximum utility in a systematic and effective way. When a set of necessary steps to increase the performance of such weaken factors of weaken districts then the expected quality of primary education is achieved.

\section{ACKNOWLEDGMENT}

In this work we are grateful to Prof. Dr.Mohammad Shahadat Hossain, Department of Computer Science \& Engineering, University of Chittagong, Bangladesh for his sound idea on Evolutionary Computing specially Evidential Reasoning.

\section{REFERENCES}

[1] School Survey Report of Second Primary Education Development Programme (PEDP-II), ,Directorate of Primary Education ,Ministry of Primary and Mass Education, Government of the Peoples' Republic of Bangladesh, pp.1-131 2007(Published 2008).

[2] Bangladesh Primary Education Annual Sector Performance Report , Government of the People's Republic of Bangladesh, Directorate of Primary Education, Second Primary Education Development Programme, pp. 1-72,May 2009.
[3] J. B. Yang and M. G. Singh, "An Evidential Reasoning Approach for Multiple Attribute Decision Making with Uncertainty," IEEE Trans. Syst.,Man, Cybern., vol. 24, no. 1, pp. 1-4, 1994.

[4] J. B. Yang and D. L. Xu, "On the Evidential Reasoning Algorithm for Multiple Attribute Decision Analysis with Uncertainty," IEEE Trans. Syst., Man, Cybern. A, vol. 32, pp. 289-304, May 2002.

[5] J. B. Yang and D. L. Xu, "Nonlinear Information Aggregation via Evidential Reasoning in Multiattribute Decision Analysis Under Uncertainty," IEEE Trans. Syst., Man, Cybern. A, vol. 32, no. 4, pp. 376-393, May 2002.

[6] J. B. Yang, "Rule and Utility Based Evidential Reasoning Approach for Multiple Attribute Decision Analysis Under Uncertainty," Eur. J. Oper.Res., vol. 131, no. 1, pp. 31-61, 2001.

[7] D. L. Xu, "Assessment of Nuclear Waste Repository Options Using the Er Approach," Int. J. of I T \& DM vol. 8, no. 3, pp. 581-607, 2009.

[8] P. Gustafsson, R. Lagerström, P. Närman, and M. Simonsson, "The Ics Dempster-Shafer how to ," unpublished

[9] Y.Wang, J. B. Yang, and D. L. Xu, "Environmental Impact Assessment using the Evidential Reasoning Approach," Eur. J. Oper.Res., vol. 174, pp. 1885-1913, 2005.

[10] Baseline Report of Second Primary Education Development Programme (PEDP-II), Government of the People's Republic of Bangladesh, Directorate of Primary Education, Second Primary Education Development Programme, pp. 1-138, June 2006

[11] S. Grover,N. H. Singh, and N. Stromquist, "The Quality of Primary Education" A Case Study of Madurai and Villupuram Districts in Tamil Nadu,India, pp. 1-77,April 2002.

[12] A F M Fazle Rabbi, "Primary Education in Bangladesh," Viability of Achieving Millennium Development Goals, pp. 1-86, 2007.

[13] M. Nurul I. Shekh, "The State of Primary Educational Quality in Bangladesh: An Evaluation” unpublished 